Institute and Clinics and served in these capacities until his first, official retirement in 1969.

After moving to Tucson, Dr Brosin joined the faculty of the Department of Psychiatry at the University of Arizona College of Medicine. He taught medical students and residents until his retirement in 1994, at the age of 90.

Dr Brosin was known internationally for his contributions to psychiatry in general and to psychoanalysis in particular. He published numerous scientific articles in academic journals, focusing on a wide variety of topics ranging from eating disorders to organic cerebral diseases. His main interest was in individual psychotherapy, psychosomatics and physicians/psychiatrists education. His influence over innumerable psychiatrists who studied under him is legendary. He was a teacher and a mentor par excellence. He was a voracious reader and possessed a library of over 5000 volumes.

Dr Brosin received wide acclaim from his colleagues as attested to by his numerous awards. He was elected President of such prestigious organisations as the American Psychiatric Association, the Group for Advancement of Psychiatry and the American College of Psychiatrists.

He was elected to the honorary fellowship of the Royal College of Psychiatrists in the UK.

He will be missed by his family and students and colleagues worldwide as a great guiding influence, a clear thinker, a gifted healer and a humble but powerful student of human behaviour.

Jose Santiago

\title{
miscellany
}

\section{The Retired Psychiatrists Group of the Scottish Division of the Royal College of Psychiatrists}

The Retired Psychiatrists Group of the College's Scottish Division has been in existence for over 16 months and has held a series of successful and enjoyable meetings. Retirement means different things to different people, with some taking up new interests and activities and some remaining active in psychiatry. However, most people like to keep in touch with former colleagues, compare notes about their lives and enjoy their company. The Retired Psychiatrists Group seeks to meet this need. Meetings have been held in Glasgow, Edinburgh and Perth and most speakers so far have been members of the group who have a remarkable range of interests and knowledge. the Group aims to include a wide variety of topics in their programme, but will leave the more technical aspects of psychiatry to the main College meetings. Possible future activities include visits to sites of historical interest, hillwalking and golf. A total of 42 Scottish psychiatrists joined the group in the first year. For further details, please contact Karen Addie, Royal College of Psychiatrists, 9 Queen Street, Edinburgh EH2 1JQ (telephone: 0131220 2910).

\section{Flexible Working/Job- Sharing National Register}

The Women in Psychiatry Special Interest Group have set up a national register which hopes to fulfil the following functions: document the number of psychiatrists in training who are currently working flexibly or in a job-share; document the number of consultants who are currently working flexibly or in a job- share; and identify psychiatrists who may be interested in job-sharing or in splitting posts into flexible jobs who can be matched on a database with psychiatrists who are interested in the same speciality and a post in the same area.

In order to achieve the above, the group would be grateful if anyone considering flexible training, even if they are not considering a job-share or parttime work at present, registered on the database so that the information provided by the group can be up to date and accurate. Following registration, changes must be communicated so that the information is kept up to date. The database is confidential and only the names of those who have expressed an interest in jobshares to potential matches who are also on the database will be circulated. Those who request information from the database will be expected to provide feedback on the outcome of their approaching potential matches. It is hoped that the database will provide information on areas where it is easier to work part-time or to share a job, and also to demonstrate inequalities across the country, thus providing valuable information about how to address potential imbalances. To register on the database, please contact Dr Moira Livingston, Database Coordinator, Women in Psychiatry Special Interest Group, Ash Court, North Tyneside General Hospital, Rake Lane, North Shields, Tyne \& Wear NE29 8NH (telephone/fax: 0191293 2749).

\section{Psychiatrist for the Mbarara University of Science and Technology, Uganda}

The Department of Psychiatry of the Mbarara University of Science and Technology is looking for a psychiatrist to head the department, train medical students and coordinate and supervise the mental health team and activities. Mbarara is a small University with a Faculty of Medicine, Science Education and Development Studies. The medical curriculum emphasises community oriented learning to train doctors suitable to work in rural Africa. Resources in terms of personnel, equipment and drugs are often limited. The Department of Psychiatry, with a small multi-disciplinary team, runs an in-patient unit of 20 beds, extensive out-patient services and training programmes for medical students. The mental health programme, which has been supported by Oxfam, includes the following: training and supervision of health care workers in the district and neighbouring districts since 1991; assisting traumatised, displaced people and refugees in various areas, through various interventions; collaborating with traditional healers and the counsellors training programme. For further details of this vacancy, please contact Professor Eldryd Parry at The Tropical Health and Education Trust (THET), 24 Eversholt Street, London NW1 1AD (telephone: 0171611 8705/6; fax: 0171611 0683).

\section{New publication}

Butterworth-Heinemann are the publishers of Psychotherapy in Practice: A Life in the Mind, by Jennifer Stein and Samuel M. Stein. This collection of interviews provides valuable insights into the work and lives of a number of leading practitioners in psychotherapy. Various questions and problems, which practitioners often come across, but which tend to remain unresolved throughout their careers, form the subject of these enlightening and thought-provoking discussions. The book shows how these psychotherapists have approached different problems, how they worked through them with service users and their 